\section{Interpreting noninvasive prenatal paternity tests}

To the Editor: We read with great interest the brief report by Ryan et al. ${ }^{1}$ on noninvasive prenatal paternity testing using the Human-CytoSNP-12 array. While the report brings state-ofthe-art technological innovation through the sheer volume of 300,739 single-nucleotide polymorphisms and thus increases the amount of available information by several orders of magnitude, we feel that the authors' interpretation of the test is unconventional.

Paternity testing is used to inform a variety of settings, including alimony, inheritance, immigration, rape, and incest cases. In all such cases, correct interpretation is paramount. Therefore, forensic geneticists have expended much effort to find a comprehensive, logical approach that can be used as a biostatistical standard for ISO17025-accredited laboratories. Such a standard has been published ${ }^{2}$ and can be easily adopted by any laboratory that offers paternity testing. The core of the recommendation is that interpretation of the genetic results should be performed from a Bayesian perspective, using likelihood ratio (paternity index) terms. Such interpretation is designed to reveal factual errors and to avoid logical errors, even if applied by genetic laymen (i.e., in a court of law). According to this recommendation, paternity investigation consists of three important steps. First, fundamental, empirical, and specific assumptions of the calculation and hypotheses to be compared are delineated. Second, the weight of the evidence is calculated in the form of a likelihood ratio (paternity index), where the numerator is the probability of the genetic test results given the alleged man is the father and the denominator is the probability of the genetic test results given the alternative hypothesis (i.e., an unknown, unrelated man is the father of the child). Third, if prior probability of paternity is stated and defended, posterior probability of paternity can be calculated by combining prior probability and the likelihood ratio.

Instead, Ryan et al. ${ }^{1}$ avoid using prior probability, a hypothesis statement, and likelihood calculation by describing a diagnostic potency of the test using the term " $100 \%$ accuracy." This term is misleading in the field of paternity and kinship testing. If the diagnostic potency of the new paternity test is to be described by a number, the usual way is to use the probability of excluding the wrongfully alleged man (probability of exclusion). For unlinked circulated DNA in plasma markers without mutation and population substructure, it would be

$$
\begin{aligned}
P E= & +\sum_{i=1}^{n} p_{i}^{3}+4 \sum_{i=1}^{n} p_{i}^{4}-6 \sum_{i=1}^{n} p_{i}^{5}-2 \sum_{i=1}^{n} p_{i}^{2} \\
& +6\left(\sum_{i=1}^{n} p_{i}^{3}\right)\left(\sum_{i=1}^{n} p_{i}^{2}\right)-4\left(\sum_{i=1}^{n} p_{i}^{2}\right)^{2}
\end{aligned}
$$

where $n$ is the number of alleles and $p_{i}$ is the allelic frequency of $i$ th allele. On the condition that the array is able to separate the child's DNA from the mother's circulating DNA (to distinguish what allele the mother with an $\mathrm{AB}$ genotype gave to the child to produce an $\mathrm{ABC}$ maternal plasma genotype), probability of exclusion would retain the standard form of:

$$
P E=\sum_{i=1}^{n} p_{i}\left(1-p_{i}\right)^{2}-\sum_{i=1}^{n-1} \sum_{j=i+1}^{n} p_{i}^{2} p_{j}^{2}\left(4-3 p_{i}-3 p_{j}\right)
$$

(http://www.isag.us/Docs/consignmentforms/Exclusion_probability.pdf).

However, the preferable form of reporting HumanCytoSNP-12 array results in paternity testing from plasma would be the paternity index. The paternity index for every locus can be calculated as $1 / p_{A}$ for (the mother's, the circulating DNA mixture's, and the alleged man's genotype) constellations $\mathrm{AA}, \mathrm{AA}, \mathrm{AA} ; \mathrm{BB}, \mathrm{AB}, \mathrm{AA} ; \mathrm{BC}, \mathrm{ABC}, \mathrm{AA}$, and $1 /\left(2 p_{\mathrm{A}}\right)$ for trio genotype constellations $\mathrm{AA}, \mathrm{AA}, \mathrm{AB} ; \mathrm{BB}, \mathrm{AB}, \mathrm{AB} ; \mathrm{CC}$, $\mathrm{AC}, \mathrm{AB} ; \mathrm{BC}, \mathrm{ABC}, \mathrm{AB} ; \mathrm{BC}, \mathrm{ABC}, \mathrm{AC} ; \mathrm{BC}, \mathrm{ABC}, \mathrm{AD}$ (http:// dna-view.com/placental.htm). Again, on the condition that the array is able to separate the child's DNA from the mother's circulating DNA, the paternity index would retain the standard form of $1 / p_{A}$ for (the mother's, the child's, and the alleged man's genotype) constellations $\mathrm{AA}, \mathrm{AA}, \mathrm{AA} ; \mathrm{AB}, \mathrm{AA}, \mathrm{AA} ; \mathrm{BB}$, $\mathrm{AB}, \mathrm{AA} ; \mathrm{BC}, \mathrm{AB}, \mathrm{AA} ; 1 /\left(2 p_{A}\right)$ for constellations $\mathrm{AA}, \mathrm{AA}, \mathrm{AB}$; $\mathrm{AB}, \mathrm{AA}, \mathrm{AB} ; \mathrm{AC}, \mathrm{AA}, \mathrm{AB} ; \mathrm{BB}, \mathrm{AB}, \mathrm{AB} ; \mathrm{BC}, \mathrm{AB}, \mathrm{AB} ; \mathrm{BC}, \mathrm{AC}$, $\mathrm{AB}$; $\mathrm{CC}, \mathrm{AC}, \mathrm{AB} ; \mathrm{CD}, \mathrm{AC}, \mathrm{AB} ; 1 /\left(p_{A}+p_{B}\right)$ for constellations $\mathrm{AB}, \mathrm{AB}, \mathrm{AA} ; \mathrm{AB}, \mathrm{AB}, \mathrm{AB}$, and $1 /\left(2\left(p_{A}+p_{B}\right)\right)$ for constellation $\mathrm{AB}, \mathrm{AB}, \mathrm{AC}$ (http://dna-view.com/patform.htm). The total paternity index can be reached, even for linked markers, by multiplying individual paternity indexes because in maternal plasma we consider only sets of single meioses and no correction for linked loci is needed.

Because the number of new prenatal testing methods is likely to increase even further, ultimately leading to multiparallel sequencing of the whole genome, we suggest that the standards, once established, be followed before they are proven invalid. It has been shown many times that using nonstandard methods to present paternity test results can lead to misunderstandings and erroneous conclusions. ${ }^{3}$ 


\section{LETTER TO THE EDITOR}

DISCLOSURE

The authors declare no conflict of interest.

Jiř́ Drábek, $P h D^{1}$ and Giulia Cereda, $M S c^{2,3}$

${ }^{1}$ IMTM, Faculty of Medicine and Dentistry, Palacky University Olomouc, Olomouc, Czech Republic; ${ }^{2}$ School of Criminal Justice, University of Lausanne, Lausanne, Switzerland; ${ }^{3}$ Mathematical Institute, University of Leiden, Leiden, The Netherlands. Correspondence: Jiří Drábek (jiri.drabek@upol.cz)

\section{REFERENCES}

1. Ryan A, Baner J, Demko Z, et al. Informatics-based, highly accurate, noninvasive prenatal paternity testing. Genet Med 2013;15:473-477.

2. Gjertson DW, Brenner $\mathrm{CH}$, Baur MP, et al. ISFG: recommendations on biostatistics in paternity testing. Forensic Sci Int Genet 2007;1:223-231.

3. Kaye $\mathrm{DH}$. The probability of an ultimate issue: the strange cases of paternity testing. lowa Law Review 1989;75:75-109.

doi:10.1038/gim.2014.100

by the New York State Department of Health, and a review of our test methodology and analytics by the American Association of Blood Banks' Relationship Testing Standards Committee has found them to be appropriate for relationship testing.

In response to specific comments by Drs. Drabek and Cereda, we believe that they have conflated the projected accuracy of the test and the observed accuracy in the study cohort. Our claim that the method determined paternity with $100 \%$ accuracy in a trial with 36,400 paternity tests with known results is correct. Moreover, although the method suggested by Drs. Drabek and Cereda is appropriate when pure fetal DNA has been isolated, as stated above, it is not currently possible to use this method prenatally in a noninvasive manner.

\section{DISCLOSURE}

All authors are employees of Natera, with stock or options to hold stock in the company.

Allison Ryan, $P h D^{1}$, Zachary Demko, $P h D^{1}$, Styrmir Sigurjonsson, $P h D^{1}$ and Matthew Rabinowitz, $P h D^{1}$

${ }^{1}$ Natera, San Carlos, California, USA. Correspondence: Matthew Rabinowitz (mrabinowitz@natera.com) tal paternity testing. However, the fetal cell-free DNA in maternal plasma is mixed in with a much larger amount of maternal cell-free DNA and cannot be separated, precluding the use of traditional paternity testing methods. To overcome this challenge, we developed a new analytical method appropriate for performing paternity testing on fetal-maternal DNA mixtures.

In keeping with our common desire to establish standards that ensure accuracy of new paternity testing methodologies, we are working with several nationally recognized organizations to this end. Our noninvasive prenatal paternity test has been approved

\section{REFERENCES}

1. Drábek J, Cereda G. Interpreting noninvasive prenatal paternity tests. Genet Med 2014;16:793-794.

2. Ryan A, Baner J, Demko Z, et al. Informatics-based, highly accurate, noninvasive prenatal paternity testing. Genet Med 2013;15:473-477.

doi:10.1038/gim.2014.99 